\title{
Towards an understanding of technology fit and appropriation in business networks: evidence from blockchain implementations
}

\author{
Stefan Seebacher ${ }^{1} \cdot$ Ronny Schüritz ${ }^{1} \cdot$ Gerhard Satzger $^{1}$
}

Received: 28 September 2019 / Revised: 21 September 2020 / Accepted: 25 October 2020 /

Published online: 10 November 2020

(c) The Author(s) 2020

\begin{abstract}
Existing information systems research thoroughly explains how task-technology fit and appropriation affect performance on an individual or group level. This was appropriate for many years, as technology is typically used to fulfill a certain task on these levels. Today, however, companies are tightly interconnected and rely on business networks to develop, produce, and deliver products and services. They collaboratively engage in joint implementation and utilization of new technologies that are applied and integrated into their business processes. These technologies, such as the newly introduced blockchain technology, operate across business networks and, thus, unfold their benefits not only on an individual or group level, but ideally on a network level. On this level, though, knowledge of the application and performance of information technology is still scarce. To drive the performance of technology in such networks, we investigate the impact of fit and technology appropriation on a network level. Due to the technology's expected impact and characteristics, we select blockchain technology to explore potential factors, impacting fit, appropriation and, in turn, performance. We draw upon a set of interviews with experts that have implemented blockchain solutions in large business network settings. Based on our analysis, we propose a comprehensive model elevating the Fit-Appropriation Model to a network level. We contribute to the general understanding of technology utilization and performance by extending existing theory to a network-level

Stefan Seebacher

stefan.seebacher@kit.edu

https://www.ksri.kit.edu/index.php

https://www.ksri.kit.edu/english/team_stefan_seebacher.php

Ronny Schüritz

ronny.schueritz@kit.edu

https://www.ksri.kit.edu/english/team_ronny_schueritz.php

Gerhard Satzger

gerhard.satzger@kit.edu

https://www.ksri.kit.edu/english/team_gerhard_satzger.php

1 Karlsruhe Institute of Technology (KIT), Karlsruhe Service Research Institute (KSRI),

Kaiserstr. 89, 76133 Karlsruhe, Germany
\end{abstract}


perspective. Using insights on blockchain implementations as our empirical base, we also provide guidance to business leaders, intending to connect their partners through blockchain technology.

Keywords Blockchain technology $\cdot$ Business network $\cdot$ Fit-appropriation · IOIS performance

\section{Introduction}

Today, company success increasingly relies on the capability to build and manage partnerships and business networks for the development and provisioning of products and services (Amaral et al. 2011; Ritter and Gemünden 2003), thereby, integrating resources and capabilities of the involved network partners (Gulati et al. 2000 ; Hargadon and Sutton 1997). Information technology has contributed and accelerated this development by serving as an enabler for efficient communication and the exchange of information across organizations. This facilitates the transformation from working and thinking in narrow value chains to adopting a much broader business network perspective (Weill and Woerner 2015).

Interorganizational information systems (IOIS) have become the fabric and binding element between partners in a business network. Such systems can be built upon different technologies (Iacovou et al. 1995), which are appropriated by different organizational entities in a business network. Blockchain technology is a promising and novel means for creating IOIS (Tapscott and Tapscott 2017), reducing the need for third party involvement while also providing tamperresistance and facilitating the creation of trusted and certain systems (Michelman 2017). Participants of an IOIS that is built upon blockchain rely on the technology's algorithms. They are not dependent on intermediaries or the reputation of a company to provide trust in the network (Rauchs et al. 2018). Furthermore, blockchain is a very versatile technology and provides the means for customization, as it is not limited to a specific field of application or purpose (Glaser 2017). As multipurpose technology, it can be adopted in various IOIS settings, which again underscores its potential impact on the development of future IOIS.

While published research on networks and IOIS has covered a broad variety of research subjects, e.g., concerning the adoption of IOIS (Chwelos et al. 2001; Holland et al. 1992; Hsu et al. 2015; Meier and Sprague 1991) and system performance (Liang 2015; Wu and Chang 2012), knowledge about the impact of fit and appropriation of technology in IOIS is still very limited. On an individual and group level, the interplay between technology and social structures as well as their impact on individual and group level performance has thoroughly been discussed (Dennis et al. 2001; Goodhue and Thompson 1995). However, since the technology of an IOIS is adopted and used by different organizations, it is also necessary to develop an understanding of task-technology fit and technology appropriation on a network level to exploit the full potential of IOIS in today's 
business networks and, thus, enable the efficient and effective utilization of technologies like blockchain.

To explore the impact of task-technology fit and technology appropriation in business networks, we aim to answer the following research question: How do task-technology fit as well as technology appropriation influence the performance of an IOIS-based business network? We study IOIS based on blockchain technology, since it is driving the convergence of organizations towards a network-based economy. We base our research on a series of interviews with business and IT managers who have already realized blockchain solutions in business networks. Building upon a qualitative content analysis (Krippendorff 2013), we identify a series of technological, organizational and network-related factors that influence the performance of IOIS. We interpret these results in the context of Task-Technology Fit Theory as well as the Fit-Appropriation Model to propose a new FitNetwork Model.

We aim to contribute to the knowledge of fit, appropriation, and performance by extending the existing perspective to a network level. Thereby, we contribute to the development of IOIS, uncovering critical influencing factors that have to be accounted for during implementation as well as the operation of such systems. The Fit-Network Model provides concrete guidance to business and IT managers intending to connect their business partners in an IOIS based on a technology such as blockchain.

This paper is structured as follows: First, we provide an overview of related work, addressing the network paradigm, IOIS and theoretical foundations on information technology utilization and performance. In the methodology section, we describe our data acquisition and analysis process. Next, we present the developed Fit-Network Model by, first, describing its boundary conditions and, second, by detailing its components as well as foundational propositions. Evidence for these elements is provided based on both the performed interviews and available literature. We conclude the paper by critically examining our work and presenting potential avenues for future research.

\section{Related work}

This research explores how task-technology fit as well as technology appropriation impact the network performance of an IOIS. Therefore, we illustrate the shift in academic literature towards a network paradigm, its importance as well as the role of information technology in interorganizational systems. Furthermore, we present insights on blockchain technology, its characteristics, and application in IOIS. We close the section by providing an overview of theoretical models that address technology usage as well as resulting outcomes. In particular, we present the underlying theoretical models of Task-Technology Fit and Fit-Appropriation, dealing with technology performance and utilization on an individual or group level. These models are subsequently adapted to meet the requirements of assessing technology utilization in business networks. 


\subsection{The network paradigm and information technology}

In the past decades, companies have increasingly become reliant on their partners in business networks concerning value creation and delivery (Amaral et al. 2011; Möller and Halinen 1999). They have transformed from vertically integrated to highly specialized organizations (Achrol 1996), which are embedded in a system of business relationships between diverse business entities (Anderson Hakan et al 1994; Blankenburg Holm et al. 1999). Therefore, the "ability to handle, use, and exploit interorganizational relationships" (Ritter and Gemünden 2003, p. 745) has become a key driver for a company's success (Gulati et al. 2000).

The increased importance of networks and the emergence of a network paradigm went hand in hand with a rise of theoretical contributions in organizational research addressing network-related issues (Borgatti and Foster 2003). This broadened view opened up a new perspective for exploring and analyzing organizations, while also expanding "the universe of observed phenomena" (Zaheer et al 2010, p. 62). Relationships, their formation and impact on organizational as well as network-related outcomes (Ahuja 2000; Anderson et al. 1994; Lorenzoni and Lipparini 1999; Zaheer et al. 2010), have been a key issue in network research. For instance, different reasons exist for the emergence of interorganizational relationships. Teo et al. (2017) analyze the impact of institutional pressures and Oliver (1990) assesses critical contingencies as determinants for relationship formation. Palmatier et al. (2007) leverage the perspectives of commitment-trust, dependence, transaction cost economics, and relational norms to develop an integrated model of interfirm relations.

With regard to performance as an organizational or network-related outcome, Mouzas (2006) underscores the importance of differentiating between efficiency and effectiveness and states that in order to assess performance, it is necessary to take into account measures for both efficiency and effectiveness. Being able to access and leverage resources, e.g., data of another company, is a key element for driving efficiency and effectiveness (Lorenzoni and Lipparini 1999). In this context, business networks should be seen as a means for accessing rather than acquiring information (Grant and Baden-Fuller 2004). The development of a business network is accompanied by the emergence of reciprocal communication structures (Powell 1990). In general, a distinction can be made between informal and formal structures, enabling access to information (Ritter and Gemünden 2003).

The advent of information technology and resulting information systems in business networks have facilitated the exchange of information across organizational boundaries (Johnston and Vitale 1988). To better understand the role and impact of IT in interorganizational systems, IS research has addressed, amongst others, influencing factors of IOIS adoption (e.g., Barrett and Konsynski 1982; Chwelos et al. 2001; Hekkala and Urquhart 2013; Meier and Sprague 1991; Rodón and Sesé 2010) as well as implications of IOIS integration (e.g., Allen et al. 2014; Sankaranarayanan and Sundararajan 2010). Understanding the functioning of a system goes hand in hand with understanding factors that influence the effectiveness as well as efficiency (Neely et al. 2005). Therefore, several publications have assessed IOIS performance. Da Silveira and Cagliano (2006) analyze IOIS adoption with regard to the performance dimensions of cost, delivery, quality, and flexibility in a dyadic as well 
as multilateral context. They propose that dyadic IOIS contribute positively to the fulfillment of "performance priorities of stable supply networks" (Da Silveira and Cagliano 2006, p. 246), which are cost-, delivery-, and quality-oriented. Multilateral IOIS contribute to flexibility and quality performance goals, and are, therefore, especially suited for dynamic settings, such as innovation networks. Liang (2015) combines a balanced scorecard with the analytical hierarchy process, as a means to prioritize different elements of the multi-criteria problem to estimate the performance of an IOIS in a supply-chain context. Although the underlying balanced scorecard integrates performance indicators regarding financial, internal process, and customer dimensions, the fit between a technology and a business problem as well as technology appropriation are not considered. Similarly, Wu and Chang (2012) make use of a balanced scorecard to analyze the performance implications of different stages in the diffusion of an electronic supply chain management (e-SCM) system. In their research framework they depict the impact of these stages on, amongst others, business process performance as well as financial performance. Rai et al. (2006) analyze the interplay between IT and process integration and, in turn, their impact on firm performance. They suggest that if a company is able to integrate the IT infrastructure of an information system, this contributes positively to the integration of supply chain processes. The resulting, enhanced flows of information lead to higher process efficiency and, therefore, performance. As an IOIS may connect a large set of heterogeneous participants, Dong et al. (2017) analyze the impact of institutional distance between these participants, its effect on knowledge-sharing and, eventually, on the joint performance of the collaborating organizations. They show that normative and cognitive aspects of institutional distance affect knowledge-sharing and performance.

\subsection{Blockchain-based IOIS}

Blockchain technology is a new means to set up interorganizational information systems Pedersen et al. 2019). Existing technologies in interorganizational information systems have already served as a "communications infrastructure to electronically transfer information, with minimal effort and time lag, resulting in the easy availability of information" (Premkumar 2000, p. 58). Yet, the novelty of blockchain technology becomes apparent when looking at its inherent characteristics to reduce the need for centralized coordination and authoritative intervention by third parties (Rauchs et al. 2018). Because of its characteristics, the technology is expected to substantially impact the way digital interaction takes place, having the potential to affect a variety of different industries (Tapscott and Tapscott 2017).

Blockchain technology is currently one of the most noticed information technologies and can broadly be defined as a distributed database shared by a peer-to-peer network, in which the technology-and not an intermediary-serves as enabler of validated and immutable transactions in a network (Glaser 2017). Blockchain technology facilitates the technology-based formation of a consensus among the participants concerning the state of the database, e.g., with regard to the storage of information or the execution of transactions (Iansiti et al. 2017). There is a broad 
variety of design options and representations of blockchain-based systems, ranging from open and distributed to centralized and closed (Kannengießer et al. 2019; Rauchs et al. 2018; Scholz and Stein 2018). While the dominant stream of research on blockchain technology addresses technical aspects of the technology (Yli-Huumo et al. 2016), blockchain technology equally entails organizational implications. Diverse parties are enabled to collaborate and engage in a process of mutual value creation in networks (Iansiti et al. 2017). Blockchain business networks are peer-topeer networks of business entities that aim to achieve a common objective and are linked by blockchain technology. In a blockchain-based information system, information is shared throughout a network, providing complete transparency. Thereby, blockchain induces trust and certainty about a system's state based on participants' consensus (Glaser 2017). As the technology facilitates the transfer of information while reducing the need for intermediaries, blockchain is expected to significantly decrease transaction costs. This raises the question regarding the future meaning and nature of a single organization (Scholz and Stein 2018) and, thereby, underscores the importance of the respective business network in which such an organization is embedded. Therefore, expanding the knowledge on task-technology fit and technology appropriation on a business network level is especially important to efficiently and effectively set up and maintain blockchain-based information systems.

Due to blockchain technology's inherent characteristics as well as its potential to fundamentally shape the design of future IOIS, we draw upon blockchain-based IOIS as the object of investigation to conduct our analysis and build our research model.

\subsection{Technology utilization and performance}

Our goal is to explore the impact of task-technology fit and technology appropriation in IOIS. The constructs fit and appropriation can be allocated to a broader set of theoretical contributions dealing with technology adoption and usage as well as related outcomes. In this section, we provide an overview of several theoretical contributions that have been recognized for their explanatory power, addressing the mentioned topics.

One group of theoretical models is, at its core, based on the Technology Acceptance Model (TAM), which was initially introduced by Davis (1986). An individual's attitude towards using a technology is shaped by the individual perception of ease of use and usefulness of the technology, resulting in an intended behavior based upon attitude and perceived usefulness. Thereby, technology usage is the result of an individual's belief system (Davis 1986). In the past, the original model was subject to a multitude of extensions and adjustments (e.g., Amoako-Gyampah and Salam 2004; Dishaw and Strong 1999; Venkatesh and Davis 2000). Building upon and integrating TAM, the Unified Theory of Acceptance and Use of Technology (UTAUT) (Venkatesh et al. 2003) comines eight models and theories to contribute to a better understanding of intention to use and the actual use of a technology. UTAUT has been applied in a variety of research inquiries, such as extending UTAUT with trust considerations. Yuan et al. (2019) propose a model that conceptualizes the continuous 
usage intention of a service and apply it in the context of internet banking services. They build upon and integrate the commitment-trust theory (CTT) and UTAUT. Their results indicate that trust and commitment contribute positively to continuous usage intention. Similarly, Wu et al. (2014) extend UTAUT with the constructs user satisfaction, credibility trust, and benevolence trust to assess the continuous usage intention of social media networks. While all of these constructs impact continuous usage intention, the authors' findings underscore the significant influence of benevolence trust. Wang et al. (2015) analyze the intention to use a recommender system, also extending UTAUT with a trust construct. Furthermore, they assess whether different types of recommender systems and products assume a moderating role for the intention to use a particular system. Their results indicate that while the type of recommender system acts as a determinant for the intention to use a system, this is not the case for the type of product.

Another major theoretical contribution for analyzing information system usage is the IS success model (DeLone and McLean 1992, 2003). In their updated version of this model, the authors attribute the success of an information system to the relationship of the constructs: information quality, system quality, service quality, user satisfaction, intention to use/ use, and net benefits (DeLone and McLean 2003). Ever since its introduction, the IS success model has been extended and applied multiple times (e.g., Lai et al. 2013; Marjanovic et al. 2016; Noh and Lee 2016; Shin et al. 2018). For instance, Marjanovic et al. (2016) base their analysis of an e-learning system on the IS success model constructs of system quality, system use, user satisfaction, and net benefits, while also integrating user performance into their assessment. Noh and Lee (2016) integrate elements of the IS success model and TAM to analyze the usage of banking applications for smartphones, while also examining a mediating role of trust. Amongst others, their results indicate that trust takes on a moderating role in the relationship between system quality, service quality and the intention to use, positively influencing the relationship. Whereas, in the case of information quality, this effect cannot be confirmed.

Task-Technology Fit Theory (TTF) attributes the utilization of a technology to how well the characteristics or functionality of a specific technology can address the characteristics of a given task (Goodhue and Thompson 1995). The degree of alignment between an information system and a task determines the outcome regarding technology utilization, affecting system performance. By focusing on task and technology characteristics instead of individual belief systems, TTF argues that a technology is used as long as its application is beneficial in terms of productivity or efficiency and matches the task requirements (Goodhue 1995). The concept of task-technology fit is taken up and further extended by the Fit Appropriation Model (FAM) (Dennis et al. 2001), which "proposes that the relationship between fit and performance is moderated by the user's appropriation of the technology" (Schmitz et al. 2010, p. 1). FAM is theoretically grounded in the decision theorist as well as the institutionalist schools of thought (Dennis et al. 2001). FAM provides the means for integrating task-technology fit with institutionalist views, which build upon Adaptive Structuration Theory (AST) (DeSanctis and Poole 1994). AST contributes to the analysis of technology utilization on an individual and group level, arguing that both technology as well as human action provide structures that contribute to 
social evolution, e.g., with regard to social structures or behaviors. In a FAM context, the appropriation of such structures has implications on individual or group performance (Dennis et al. 2001).

For the purpose of this research, we draw upon FAM as it provides the means to integrate a rational approach (Dishaw and Strong 1999) that matches task requirements and technology characteristics (Goodhue 1995) with an institutionalist perspective (Mignerat and Rivard 2009) that incorporates behavioral and social aspects. Goodhue (1995) groups theoretical models, such as TAM, UTAUT or the IS success model, under the category of 'utilization oriented research'. In these models, the utilization of a technology is mostly impacted by a user's attitudes and beliefs. Yet, Goodhue (1995) argues that such considerations neglect that there are systems in which utilization might not be voluntary and in which performance is rather dependent on a task-technology fit. FAM draws upon this argument and shifts attention from embracing a user's attitude with regard to technology utilization towards an understanding of social and technological processes influencing the performance of such systems. Thereby, FAM integrates both a 'utilization focus' and 'fit focus' (Goodhue 1995) and provides the theoretical grounding to comprehensively analyze information systems (Dennis et al. 2001).

However, most of the existing studies applying TAM, UTAUT, IS success model, TTF, or FAM address issues on an individual or group level. Yet, the network paradigm and the utilization of technology across entire business networks have become increasingly important. We argue for an extension of FAM to enable the analysis of business networks consisting of multiple, heterogeneous parties, integrating a networking technology, such as blockchain.

\section{Methodology}

Although information systems make a significant contribution to the success and performance of interacting organizations (Da Silveira and Cagliano 2006), knowledge about the impact of fit and appropriation of technology in IOIS is still very limited. To inductively contribute to the theoretical understanding, we abstract from exploratory expert interviews (Eisenhardt and Graebner 2007) and build upon blockchain-based IOIS as our empirical unit of analysis.

For identifying suitable interview partners and collecting the underlying data, we employed a generic purposive sampling (Bryman 2016). We applied the following pre-defined criteria (Ritchie and Lewis 2003): The interviewees were business or technical experts, who have played a significant role in at least one blockchain project in their own organizations or as a service provider for others. Each blockchain project aimed at connecting different parties of a business network. Furthermore, we intended to incorporate the perspectives of different industries, which also influenced the selection of potential interview partners. In total, we collected eleven interviews, serving as the basis for our further analysis and research model development (cf. Table 1).

We followed a semi-structured approach for conducting the interviews. Thereby, we ensured similarity concerning the general structure of each interview 
Table 1 Overview of interviews

\begin{tabular}{lllll}
\hline No & Technical expert & Business expert & Company & Industry \\
\hline 1 & $\checkmark$ & & Alpha & Multinational technology consulting firm \\
2 & & $\checkmark$ & & \\
3 & & $\checkmark$ & Beta & Multinational technology provider \\
4 & $\checkmark$ & & \\
5 & $\checkmark$ & & Gamma & Manufacturing, engineering technology, mobility \\
6 & $\checkmark$ & & Delta & Manufacturing, engineering technology, mobility \\
7 & $\checkmark$ & & \\
8 & $\checkmark$ & & Epsilon & Electric utilities \\
9 & $\checkmark$ & & Eta & Logistic, engineering technology, mobility \\
10 & $\checkmark$ & & & Logistic, engineering technology, mobility \\
11 & & $\checkmark$ & & \\
\hline
\end{tabular}

as well as the comparability of the respective results. Yet we were still able to account for the particularities within each interview (King 2004). Although we were interested in elaborating technology fit and appropriation on a network level, we refrained from explicitly referencing and building upon elements of FAM (Dennis et al. 2001) in our interview guide. This enabled us to gain a broad range of information from the interviewees, while also being able to indirectly gather data on fit and appropriation in blockchain-based business networks. Our interview guideline was structured along the following dimensions: We focused on both the implementation of blockchain solutions and the establishment of a blockchain-based business network - for each we collected information on the processes as well as the challenges associated with them. During the interviews, we posed open questions and probed for clarification and additional insights (Ritchie and Lewis 2003). This includes, amongst others, questions such as 'What are critical factors for the success of a blockchain implementation?', 'What are aspects fostering the collaboration among potential partners?' and 'What are challenges in the realization of a blockchain-based business network?'.

All interviews were conducted via telephone and their duration varied between 40 and $90 \mathrm{~min}$. Before conducting the actual interview, we asked the interviewees for their consent to tape the conversation. The audio files were then transcribed to serve as basis for the subsequent data analysis. We followed a qualitative content analysis approach (e.g., Bengtsson 2016; Krippendorff 2013) to iteratively engage in the analysis of the interview material and the development our research model. On the one hand, we drew upon FAM as theoretical lens, forming a general set of categories that guided the analysis of the interview material. On the other hand, we applied an open coding approach to uncover concepts that are connected to the integration, application, and effects of blockchain technology in a business network. Open coding enabled us to retain the flexibility to incorporate potentially new aspects with regard to technology utilization in a business network (Charmaz 2006). While a single researcher created a first coding of the interviews, the 
progress of the coding system was regularly discussed and critically examined with a set of 2 fellow researchers in regular debriefing sessions. While these sessions helped raise and check the validity of the coding system, they were also used to integrate the codes with the general set of categories derived from FAM and to engage in a theorization process. Thereby we were able to identify aspects as well as their relationships, influencing technology fit, appropriation and performance on a network level. Throughout our model development, we combined both the analysis of the interview material as well as available literature on business networks. This process eventually enabled us to vertically borrow (Whetten et al. 2009) constructs of FAM while also allowing to identify additional aspects.

\section{Fit-network model}

In this section, we first dwell on the theoretical boundaries of the research model, addressing the level of analysis as well as explanatory goals. Subsequently, we present the developed Fit-network model by specifying the derived constructs and providing propositions for their causal relationships.

\subsection{Boundaries of the model}

The developed research model is subject to a variety of boundary conditions, strengthening its explanatory power, while also delimiting its field of application. Usually, the universal applicability of a research model and likewise of its constructs cannot be warranted. Especially in organizational research, "constructs tend to be highly sensitive and contingent to contextual conditions" (Suddaby 2010, p. 348). Therefore, information on assumptions regarding space and time, as well as implicit assumptions of the researchers have to be provided (Bacharach 1989).

Our conceptual model comprises a multi-level perspective. We intend to study task-technology fit as well as technology appropriation in a business network. We analyze different levels of social and technological processes influencing the performance of such systems. More specifically, our underlying units of analysis are strategic initiatives, which pursue the development of a joint blockchain-based application, thereby forming an interorganizational information system. The constructs of the research model address either pair, firm or network level structures of a technology-based business network. Instead of bridging the so-called micro-macro divide between an individual and organizational level (Klein et al. 1999), our goal is to integrate an organizational and network perspective. This is necessary to blend the different levels of causal relationships, as the structure and consequences of a network define the "context for action and [provide] opportunities and constraints on behavior" (Borgatti and Li 2009, p. 1000).

The Fit-Network Model aims at uncovering and explaining implications of fit and appropriation in IOIS-based business networks, using blockchain projects as a proxy for a new IOIS technology. Until now, only a few blockchain applications or cases are available (Scholz and Stein 2018), and often aspired initiatives do not surpass 
a proof of concept or prototyping phase (Fridgen et al. 2018). The early stage is especially crucial as a certain degree of benefits and performance, resulting from the introduction of the blockchain-based IOIS, have to be achieved, convincing the involved participants to fully invest in the novel information system. We base our analysis on interviews with experts that have gone through such an early project phase and sampled perspectives from multiple industries and fields of application.

We build upon the implicit assumption that both individuals and organizations act as agents, following their individual agendas. This influences their behavior. To this end, the notion of agency describes "the capacity to transpose and extend rules to new contexts" (Sewell Jr 1989, p. 22). Even though individuals and respectively organizations are embedded in certain structures, such as an organization or a business network, they may act upon their own goals and rules-their own "free will" (Leonardi and Barley 2008, p. 160). Drawing upon this similarity, we vertically borrow constructs from FAM, while elevating these concepts to satisfy the network paradigm. Yet, it is necessary to reflect (Whetten et al. 2009) how the fundamental FAM constructs, namely task-technology fit as well as appropriation, can be adapted to comply with a network setting. Initially, fit is regarded as the match between technological characteristics with the task requirements of individuals (Goodhue 1995; Goodhue and Thompson 1995). This concept has also been applied in a higher level of abstraction, such as a group setting (Fuller and Dennis 2009). Similarly, we argue that fit can also be observed on an organizational level, as organizations may engage in relationships with other companies to solve certain tasks using technology. Furthermore, the appropriation of technology may also be analyzed on an organizational level and can be regarded as an aggregated individual or group appropriation. This is necessary, as the processing of an organizational task involves a variety of individuals and groups.

\subsection{Conceptual model and propositions}

Our goal is to contribute to a better understanding of task-technology fit and technology appropriation in an IOIS. The developed research model, Fit-Network Model (FNM), is grounded in our analysis of the underlying interview material while also drawing upon and extending FAM by raising its level of analysis to meet a network

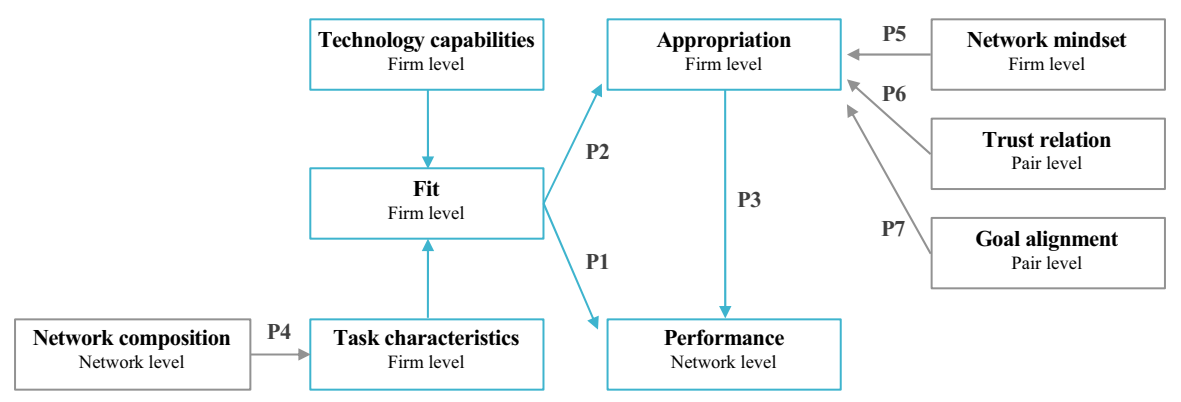

Fig. 1 Fit-network research model 
perspective. The identified constructs as well as their linkages are illustrated in Fig. 1.

\subsubsection{Performance}

Regarding the concept of performance in business networks, it is necessary to consider and balance both efficiency as well as effectiveness (Mouzas 2006). Effectiveness may, therefore, refer to aspects such as decision quality, whereas efficiency, e.g., includes time savings (Dennis et al. 2001). In a blockchain context, performance is not only desired on an individual firm level, but also has to be considered on a network scale. The benefits or performance have to be high enough to incentivize the entire business network. "Blockchain projects are destined to fail when only one company is willing to put the effort in the introduction of such a solution-It takes a community!" (Interview 7).

\subsubsection{Fit}

The concept of fit addresses the degree to which the capabilities of a technology can be leveraged to solve a specific business problem, by matching the capabilities of technology with the requirements and needs of a defined task (Goodhue 1995). Therefore, fit builds upon and matches this normative structure that influences the outcome of a technology-supported task of an organization (Fuller and Dennis 2009). Fit is conceptualized as firm level construct. We are interested in matching the respective fit between technology characteristics and task requirements for each involved organization.

Proposition 1 The greater the fit between technology and task characteristics, the greater is the potential contribution of a participating organization to the overall network performance.

\subsubsection{Appropriation}

Appropriation can be defined as the way technology is utilized while being impacted by normative structures surrounding an organization. Network-specific normative structures can be observed, influencing the way technology is appropriated in a business network, thereby, affecting its performance. Blockchain technology creates new connections and strong ties "between companies that might not have been thoroughly connected through existing infrastructure" (Interview 5). Being involved in such networks, organizations follow an individual agenda, which might or might not be in line with the overall network's interest. Based on this assumption, we deem that organizations perform their actions in a business network setting quite similar to individuals acting in groups or organizations. Adapting the individual and team perspective (Dennis et al. 2001; Fuller and Dennis 2009) to depict technology appropriation on a network level, influencing structures emerge from the characteristics of the underlying technology (Leonardi and Barley 2008), the business problem, as 
well as organizational aspects. In the case of blockchain-based business networks, these organizational factors have been identified as the firm's network mindset, existing trust relations as well as its goal alignment with other organizations. These constructs are further discussed below. When looking at individuals or groups, they choose the way they incorporate certain structures by faithfully or unfaithfully appropriating them (DeSanctis and Poole 1994). We apply this concept to an organizational level, where firms consciously or unconsciously choose the way they appropriate present structures.

Proposition 2 The greater the fit between technology and task characteristics, the higher the degree of faithful appropriation of the underlying technology by an individual network participant.

Proposition 3 A great fit and high degree of faithful appropriation of the underlying technology results in a greater contribution to the overall performance of the network.

\subsubsection{Network composition}

The degree of heterogeneity among network participants, regarding their sets of distinct capabilities, as well as the number of involved organizations, define the composition of a business network. The utility and benefits of using blockchain technology tend to depend on the size and diversity of the underlying business network. "The bigger the network of stakeholders from different industries, the greater is the potential benefit" (Interview 3). Each participating organization brings in its individual set of capabilities. These capabilities can also be regarded as resources in a network. Following a resource-based perspective, a company's relationships with other organizations can be viewed as a valuable asset (Gulati et al. 2000; Lorenzoni and Lipparini 1999) and provide the means for resource integration and co-creation of value (Vargo and Akaka 2012). Based on the distinct composition of a blockchainbased business network, different structural as well as contextual requirements arise (Kannengießer et al. 2019). Since blockchain business networks offer a platform for interaction, they are subject to network or bandwagon effects. These effects postulate that the perceived value and utility of a network depends on the number of participants (Abrahamson and Rosenkopf 1997). Furthermore, with increased network size, the withdrawal of an entity from the network can be compensated more easily by other participants. Consequently, reliance on a single, distinct network entity's resources and capabilities are diminished with growing network size. In this context, it is important to know "[...] who the most important actors in the network are, and who of them have to be integrated?" (Interview 1).

Proposition 4 A diverse set of network partners increases the set of potential tasks that can be addressed by using information technology, potentially increasing the probability of identifying a task that creates a good fit for the underlying technology. 


\subsubsection{Network mindset}

The network mindset refers to the set of assumptions, views, or notations held by a participating organization, influencing its willingness to engage in network or joint activity. That is an organization's mental model that shapes the way it makes decisions and accepts decisions of partnering organizations. Conducting business in a network setting requires the adjustment of an organization's mindset. This can, for instance, be observed in the recent discourse on open data (Enders et al. 2020). In the past, companies have often been viewed as 'lone wolves', mainly interested in their organizations (Gulati et al. 2000). Today, they find themselves as parts of bigger networks or ecosystems. In such, they might have to give up some of their former power and control, requiring a change in the organization's mindset. This was already an important issue during the advent of electronic data interchange (EDI) when a lot of effort had to be made to convince potential network participants to join an EDI network (Iacovou et al. 1995). In the case of blockchain technology, the notion and the necessity of a network mindset is even more critical, as it is based upon the paradigm shift of putting trust into technology instead of an intermediary, e.g., to validate transactions. The technology can, therefore, be regarded as a special type of network participant. "Companies used to enjoy being an intermediary and in full control of decision making, but as blockchain technology removes intermediaries and gives control to the technology and network-rethinking has to take place" (Interview 4). Taking part in a blockchain network requires organizations to get used to shared governance models, to accept that their data might be stored in databases outside of their organization (Lacity et al. 2018).

Proposition 5 An organization is more likely to faithfully use an information technology if its use does not contradict the organization's views on power, control and engagement in a business network.

\subsubsection{Trust relation}

The construct trust relation is a pair level measure, addressing how similar two organizations in a network view their relational connection based on their respective confidence in their judgment of the opposing organization, e.g., concerning reliability, predictability of behavior and fair conduct (Zaheer et al. 1998). The greater the agreement of the relational connection between two parties, the more predictable is their behavior for each of the involved parties. Existing relationships between different network parties, as well as prior knowledge about potential business partners, fundamentally determine the design of blockchain business networks. "In most cases, we know upfront who is to be involved in building and maintaining the blockchain solution" (Interview 4). This in line with the findings of Gulati and Gargiulo who state that "[...] the probability of a new alliance between specific organizations increases with their interdependence and also with their prior mutual alliances, common third parties, and joint centrality in the alliance network" (Gulati and Gargiulo 1999, p. 1430). Yet, existing relationships and knowledge alone do not suffice to ensure a successful development of an interorganizational information 
system. Institutional pressures exerted by one organization, e.g., forcing others to join a strategic initiative or to adopt a certain technology (Mignerat and Rivard 2009), may trigger defensive strategies, such as avoidance, defiance or manipulation, of another organization (Oliver 1991). Furthermore, "interfirm exchange is not created and maintained solely by boundary-spanning individuals, but rather is institutionalized in the interorganizational relationship" (Zaheer et al. 1998, p. 156). Therefore, trusted relationships contribute to the facilitation of exchange processes and outcomes in interorganizational systems (Mignerat and Rivard 2009). Appropriability also contributes to the development of trust relations, as the concept draws attention to the act of ensuring that network participants perceive to be treated fairly (Dhanaraj and Parkhe 2006). "Repeated and trust-based relationships among actors are likely to bring sustainable advantages in terms of innovation and cost economics" (Lorenzoni and Lipparini 1999, p. 332). Therefore, relationship management as well as "trust between IOS participants is essential for successful IOS" (Meier 1995, p. 135).

Blockchain technology has been introduced as a "trust machine" (Economist 2015), facilitating the interaction between untrusted parties, while also reducing the need for oversight from authorities or third parties. Undoubtedly, this holds for public and permissionless systems, in which, foremost, pseudonymous individuals interact. Yet, in an organizational setting, trust relations are still important, since the partners typically know with whom they are interacting.

Proposition 6 The higher the degree of trust relations between a firm and its partners in a technology-based business network, the more likely is a firm to faithfully appropriate a technology.

\subsubsection{Goal alignment}

The construct goal alignment is defined as mutual commitment and dependence to joint organizational objectives, resulting in adherence and compliance with overarching goals. In a business network, it is critical to "build and sustain mutual commitment [...] to engage" in a joint value-creation process, based on mutuality (Blankenburg Holm et al. 1999, p. 479). The establishment of a blockchain business network connects "a heterogeneous set of organizations, dealing with a common business case, handling a common asset" (Interview 2), who are integrating their business processes. This requires the development of a shared understanding of rules and goals. "To be part of the network, the participants are obligated to align their individual attitudes to define a common set of rules" (Interview 2).

Proposition 7 The greater the goal alignment between a firm and its partners in a technology-based business network, the more likely is a firm to faithfully appropriate a technology.

By leveraging the notions of task-technology fit as well as technology appropriation, and building upon interviews with experts that have been involved in the 
implementation of blockchain-based business networks, the presented research model and related propositions contribute to the knowledge on the application and performance of information technology at a network level.

\section{Discussion}

In today's economy, we can observe that the management of relationships, collaboration in business networks (Ritter and Gemünden 2003) as well as the effective and efficient integration of information technology in these networks (Da Silveira and Cagliano 2006; Rai et al. 2006) have a major impact on the success of an organization. IOIS facilitate interaction, binding together different parties of a business network. In this context, blockchain technology can be seen as a novel means for creating IOIS and has the potential to shape the future of technologybased collaboration (Tapscott and Tapscott 2017). We build upon blockchainbased business networks as the empirical base for our analysis. While existing studies have already striven to analyze the impact of technology on the performance of a network, fit of a particular technology to a given task, and its appropriation are not yet sufficiently understood in a network context. We add to this discourse by presenting a model that addresses these issues as well as providing propositions for the relationships of the inherent constructs.

The developed model has important implications for studying the impact of technology as well as social factors on the performance of a business network. Existing studies have already addressed technology utilization and related outcomes on an individual and group level, such as TTF or FAM (Dennis et al. 2001). Yet, IOIS are appropriated by different organizational entities in a business network and, therefore, require an assessment on a network level. We propose a comprehensive model elevating FAM to a network level while uncovering and integrating additional constructs as well as providing propositions for their relationships. Thereby, we contribute to research on networks and IOIS by identifying impact factors on the performance of IOIS. Future research may build upon our findings and conduct an in-depth analysis of the effects of the identified model elements.

Furthermore, our study has practical implications for both blockchain practitioners as well as general IOIS development projects. To the best of our knowledge, this paper is the first one to provide an overview of aspects impacting the performance of a blockchain-based business network. The presented research model builds upon the premise that a fit between technology characteristics and a particular task is essential to achieve high technology performance. Therefore, organizations should refrain from solely pursing a technology-driven implementation and from the start focus on identifying a common task or problem together with their partners (Meier 1995). However, the characteristics of a task itself are dependent on the composition of the underlying business network: As each partner contributes distinct capabilities and resources, various different tasktechnology constellations are conceivable. Keeping this in mind, organizations 
can actively engage in the design of their business networks, selecting specific partners to address distinct problems. Next to a technology fit, we argue that technology performance in a business network also depends on the appropriation of the technology by the network partners. Our model highlights three main factors for appropriation of a technology in a network: Business networks should consist of organizations that share a network mindset (Iacovou et al. 1995), build upon trusted relationships (Zaheer et al. 1998) and pursue a common goal alignment (Blankenburg Holm et al. 1999). Organizations engaging in the development of a technology-based business network may draw upon these insights to carefully select their business partners and, thereby, set the course for a long-lasting and fruitful collaboration.

\section{Conclusion}

In this research paper, we explore how task-technology fit as well as technology appropriation influence the performance of an IOIS-based business network. We build upon an exploratory study of blockchain implementation projects and the established Fit-Appropriation Model (Dennis et al. 2001) to propose the FitNetwork Model that addresses the interplay between fit and appropriation on the performance of an IOIS. Our research model vertically borrows constructs from the Fit-Appropriation Model and integrates additional elements that appreciate the influence of the composition of the business network, preceding and trusted relations of participants, the existence of a common goal alignment as well as the existence of a network mindset. Next to uncovering critical influencing factors regarding the performance of blockchain-based business networks, the FitNetwork Model guides business and IT managers intending to set up interorganizational information systems with their partners based on blockchain technology.

For our results, the following limitations have to be considered, though. First, blockchain technology is still a rather new phenomenon, which is yet under development and offers many open areas for research. While IOIS, based on other technologies, could have also been our unit of analysis, we chose to analyze blockchain-based business networks, due to the technology's expected potential and anticipated diffusion in future IOIS. Next, we pursued a qualitative and inductive approach to theory development. While we provide initial insights into the interplay between technological as well as social aspects of business network performance, further empirical testing is necessary. To this end, we shed light on constructs and propositions for their relationships.

We strive to adhere to the evaluation criteria of 'falsifiability' and 'utility' (Bacharach 1989) to evaluate our model and further illustrate its explanatory power. For instance, during the model development, debriefing sessions with fellow researchers helped to check for construct validity and logical adequacy by critically examining propositions concerning parsimony and clarity. However, additional evaluation steps may be taken in future research. First, we intend derive hypotheses based on the presented propositions to be able to measure and quantify the effects of the identified constructs of the Fit-Network Model. 
To validate the impact of the identified constructs, our goal is to perform a survey with a diverse set of blockchain projects from various industries. Although blockchain technology is still considered to be an emerging technology, lacking a large number of live applications, our goal is to analyze blockchain business networks, applying the Fit-Network Model due to two reasons: On the one hand, despite being at a potentially early stage of its development, scholars agree on its importance and impact on future applications, calling its introduction inevitable (Iansiti et al. 2017; Lacity et al. 2018). On the other hand, blockchain technology entails the capabilities to provide truly decentralized information systems. Blockchain serves as technological glue connecting the different network participants without the need for an intermediary, thereby potentially strengthening the position of each individual participant. Second, the Fit-Network Model builds upon interviews addressing blockchain implementations in business networks, the applicability of the model may be extended through the assessment of other network technologies. Thereby, apart from validating the existing results, generalizability might be strengthened and additional explanations for causal relationships might be uncovered. Therefore, we strive to perform subsequent case studies, analyzing organizations that have bonded by developing joint cloud solutions. Drawing upon expert interviews and additional case material, we also intend to uncover antecedents of our identified constructs and discuss factors that contribute to the formation of a network mindset, trusted relations and goal alignment in technology-based business networks. Third, Task-Technology Fit Theory leaves out temporal factors, taking a static perspective. While research has attempted to address this issue with regard to team or group performance by adapting the Fit-Appropriation model (Dennis et al. 2001; Fuller and Dennis 2009), the topic remains unexplored concerning the dynamics and actions within a business network. Therefore, we intend to perform a succeeding, longitudinal study on temporal effects influencing the appropriation of blockchain technology as well as the performance of blockchain-based business networks. Furthermore, the execution of a longitudinal study can contribute to the validation of the identified constructs, provide additional explanations for relationships, and potentially uncover additional propositions.

Funding Open Access funding enabled and organized by Projekt DEAL.

Open Access This article is licensed under a Creative Commons Attribution 4.0 International License, which permits use, sharing, adaptation, distribution and reproduction in any medium or format, as long as you give appropriate credit to the original author(s) and the source, provide a link to the Creative Commons licence, and indicate if changes were made. The images or other third party material in this article are included in the article's Creative Commons licence, unless indicated otherwise in a credit line to the material. If material is not included in the article's Creative Commons licence and your intended use is not permitted by statutory regulation or exceeds the permitted use, you will need to obtain permission directly from the copyright holder. To view a copy of this licence, visit http://creativecommons.org/licen ses/by/4.0/. 


\section{References}

Abrahamson E, Rosenkopf L (1997) Social network effects on the extent of innovation diffusion: a computer simulation. Organ Sci 8(3):289-309. https://doi.org/10.1287/orsc.8.3.289

Achrol RS (1996) Changes in the theory of interorganizational relations in marketing: toward a network paradigm. J Acad Mark Sci 25(1):56-71. https://doi.org/10.1177/0092070397251006

Ahuja G (2000) Collaboration networks, structural holes, and innovation: a longitudinal study. Adm Sci Q 45(3):425-455. https://doi.org/10.2307/2667105

Allen DK, Karanasios S, Norman A (2014) Information sharing and interoperability: the case of major incident management. Eur J Inf Syst 23(4):418-432. https://doi.org/10.1057/ejis.2013.8

Amaral J, Anderson EG, Parker GG, Anderson EG Jr, Parker GG (2011) Putting it together: How to succeed in distributed product development. MIT Sloan Manag Rev 52(2):51-58. https://doi. org/10.1080/09593980902776613

Amoako-Gyampah K, Salam AF (2004) An extension of the technology acceptance model in an ERP implementation environment. Inf Manag 41(6):731-745. https://doi.org/10.1016/j.im.2003.08.010

Anderson JC, Hakansson H, Johanson J (1994) Dyadic business relationships within a business network context. J Mark 58(4):1. https://doi.org/10.2307/1251912

Bacharach SB (1989) Organizational theories: Some criteria for evaluation. Acad Manag Rev 14(4):496515. https://doi.org/10.5465/amr.1989.4308374

Barrett S, Konsynski B (1982) Inter-organization information sharing systems. MIS Q 6:93-105. https:// doi.org/10.2307/248993

Bengtsson M (2016) How to plan and perform a qualitative study using content analysis. NursingPlus Open 2:8-14. https://doi.org/10.1016/j.npls.2016.01.001

Borgatti SP, Foster PC (2003) The network paradigm in organizational research: a review and typology. J Manag 29(6):991-1013. https://doi.org/10.1016/S0149-2063(03)00087-4

Borgatti SP, Li X (2009) On social network analysis in a supply chain context. J Supply Chain Manag 45(2):5-22. https://doi.org/10.1111/j.1745-493X.2009.03166.x

Bryman A (2016) Social research methods, 5th edn. Oxford University Press, Oxford

Charmaz K (2006) Constructing grounded theory: a practical guide through qualitative analysis. SAGE, London. https://doi.org/10.1016/j.lisr.2007.11.003

Chwelos P, Benbasat I, Dexter AS (2001) Research report: empirical test of an EDI adoption model. Inf Syst Res 12(3):304-321. https://doi.org/10.1287/isre.12.3.304.9708

Da Silveira GJC, Cagliano R (2006) The relationship between interorganizational information systems and operations performance. Int J Oper Prod Manag 26(3):232-253. https://doi.org/10.1108/01443 570610646184

Davis FD (1986) A technology acceptance model for empirically testing new end-user information systems. Massachusetts Institute of Technology, Cambridge

DeLone WH, McLean ER (1992) Information systems success: the quest for the dependent variable. Inf Syst Res 3(1):60-95. https://doi.org/10.1287/isre.3.1.60

DeLone WH, McLean ER (2003) The DeLone and McLean model of information system success: a tenyear update. J Manag Inf Syst 19(4):9-30. https://doi.org/10.1080/07421222.2003.11045748

Dennis AR, Wixom BH, Vandenberg RJ (2001) Understanding fit and appropriation effects in group support systems via meta-analysis. MIS Q 25(2):167-193. https://doi.org/10.2307/3250928

DeSanctis G, Poole MS (1994) Capturing the complexity in advanced technology use: adaptive structuration theory. Organ Sci 5(2):121-147. https://doi.org/10.1287/orsc.5.2.121

Dhanaraj C, Parkhe A (2006) Orchestrating innovation networks. Acad Manag Rev 31(3):659-669

Dishaw MT, Strong DM (1999) Extending the technology acceptance model with task-technology fit constructs. Inf Manag 36(1):9-21. https://doi.org/10.1016/S0378-7206(98)00101-3

Dong MC, Fang Y, Straub DW (2017) The impact of institutional distance on the joint performance of collaborating firms: the role of adaptive interorganizational systems. Inf Syst Res 28(2):309-331. https://doi.org/10.1287/isre.2016.0675

Economist T (2015) The promise of the blockchain: the trust machine. Retrieved from https://www.econo mist.com/leaders/2015/10/31/the-trust-machine

Eisenhardt KM, Graebner ME (2007) Theory building from cases: opportunities and challenges. Acad Manag J 50(1):25-32. https://doi.org/10.2307/20159839 
Enders T, Benz C, Schüritz R, Lujan P (2020) How to implement an open data strategy? Analyzing organizational change processes to enable value creation by revealing data. In: Proceedings of the European conference on information systems; ECIS 2020

Fridgen G, Lockl J, Radszuwill S, Rieger A, Schweizer A, Urbach N (2018) A solution in search of a problem: a method for the development of blockchain use cases. In: Proceedings of the Americas conference on information systems, AMCIS, 2018

Fuller RM, Dennis AR (2009) Does fit matter? The impact of task-technology fit and appropriation on team performance in repeated tasks. Inf Syst Res 20(1):2-17. https://doi.org/10.1287/isre.1070.0167

Glaser F (2017) Pervasive decentralisation of digital infrastructures: a framework for blockchain enabled system and use case analysis. In: Proceedings of the Hawaii international conference on system sciences, HICSS, 2017. https://doi.org/https://doi.org/10.24251/hicss.2017.186

Goodhue DL (1995) Understanding user evaluations of information systems. Manage Sci 41(12):18271844. https://doi.org/10.1287/mnsc.41.12.1827

Goodhue DL, Thompson RL (1995) Task-technology fit and individual-performance. MIS Q 19(2):213236. https://doi.org/10.2307/249689

Grant R, Baden-Fuller C (2004) A knowledge accessing theory of strategic alliances Robert M. Grant and Charles Baden-Fuller. J Manag Stud 41(1):61-85

Gulati R, Gargiulo M (1999) Where do Interorganizational networks come from? Am J Sociol 104(5):1439-1493. https://doi.org/10.1086/210179

Gulati R, Nohria N, Zaheer A (2000) Strategic networks. Strateg Manag J 21:203-215

Hargadon A, Sutton R (1997) Technology brokering and innovation in a product development firm. Adm Sci Q 42(4):716-749

Hekkala R, Urquhart C (2013) Everyday power struggles: living in an IOIS project. Eur J Inf Syst 22(1):76-94. https://doi.org/10.1057/ejis.2012.43

Holland C, Lockett G, Blackman I (1992) Planning for electronic data interchange. Strateg Manag J 13(7):539-550. https://doi.org/10.1002/smj.4250130706

Holm DB, Eriksson K, Johanson J (1999) Creating value through mutual commitment to business network relationships. Strateg Manag J 20:467-486. Retrieved from https://www.jstor.org/stable/30941 65

Hsu C, Lin YT, Wang T (2015) A legitimacy challenge of a cross-cultural interorganizational information system. Eur J Inf Syst 24(3):278-294. https://doi.org/10.1057/ejis.2014.33

Iacovou CL, Benbasat I, Dexter AS (1995) Electronic data interchange and small organizations: adoption and impact of technology. MIS Q 19(4):465. https://doi.org/10.2307/249629

Iansiti M, Lakhani KR, Mohamed H (2017) The truth about blockchain. Harv Bus Rev 95(1):118127. https://doi.org/10.1016/j.annals.2005.11.001

Johnston HR, Vitale MR (1988) Creating competitive advantage with interorganizational information systems. MIS Q 12(2):153-165. https://doi.org/10.2307/248839

Kannengießer N, Lins S, Dehling T, Sunyaev A (2019) What does not fit can be made to fit! trade-offs in distributed ledger technology designs. In: Proceedings of the Hawaii international conference on system sciences, HICSS, 2019

King N (2004) Using interviews in qualitative research. In: Cassell C, Symon G (eds) Essential guide to qualitative methods in organizational research. SAGE Publications Ltd, London. https://doi. org/10.4135/9781446280119.n2

Klein KJ, Tosi H, Cannella AA Jr (1999) Multilevel theory building: benefits, barriers, and new developments. Acad Manag Rev 24(2):248-253. https://doi.org/10.5465/AMR.1999.1893934

Krippendorff K (2013) Content analysis: an introduction to its methodology, 3rd edn. Sage Publications, Los Angeles, California

Lacity MC, Moloney K, Ross JW (2018) Blockchain: How to position your company for the inevitable. MIT CISR Res Brief XVII I(3):1-4

Lai JY, Kan CW, Ulhas KR (2013) Impacts of employee participation and trust on e-business readiness, benefits, and satisfaction. Inf Syst E-Bus Manag 11(2):265-285. https://doi.org/10.1007/ s10257-012-0193-9

Leonardi PM, Barley SR (2008) Materiality and change: Challenges to building better theory about technology and organizing. Inf Organ 18:159-176. https://doi.org/10.1016/j.infoandorg .2008 .03 .001

Liang YH (2015) Performance measurement of interorganizational information systems in the supply chain. Int J Prod Res 53(18):5484-5499. https://doi.org/10.1080/00207543.2015.1026614 
Lorenzoni G, Lipparini A (1999) The leveraging of interfirm relationships as a distinctive organizational capability: a longitudinal study. Strateg Manag J 20(4):317-338

Marjanovic U, Delić M, Lalic B (2016) Developing a model to assess the success of e-learning systems: evidence from a manufacturing company in transitional economy. Inf Syst E-Bus Manag 14(2):253-272. https://doi.org/10.1007/s10257-015-0282-7

Meier J (1995) The importance of relationship management in establishing successful interorganizational systems. J Strateg Inf Syst 4(2):135-148. https://doi.org/10.1016/0963-8687(95)80021-H

Meier J, Sprague RH (1991) The evolution of interorganizational systems. J Inf Technol 6(3-4):184191. https://doi.org/10.1057/jit.1991.32

Michelman P (2017) Seeing Beyond the Blockchain Hype. MIT Sloan Manag Rev 58(4):17-19. https ://doi.org/10.1007/s00146-013-0456-0

Mignerat M, Rivard S (2009) Positioning the institutional perspective in information systems research. In: Sauer C, Lacity MC (eds) LP, Willcocks. Formulating research methods for information systems: Volume 2, Palgrave Macmillan UK, London. https://doi.org/10.1057/9781137509888_4

Möller KK, Halinen A (1999) Business relationships and networks: managerial challenge of network era. Ind Mark Manag 28(5):413-427. https://doi.org/10.1016/S0019-8501(99)00086-3

Mouzas S (2006) Efficiency versus effectiveness in business networks. J Bus Res 59(10-11):11241132. https://doi.org/10.1016/j.jbusres.2006.09.018

Neely A, Gregory M, Platts K (2005) Performance measurement system design: a literature review and research agenda. Int J Oper Prod Manag 25(12):1228-1263. https://doi.org/10.1108/01443 570510633639

Noh MJ, Lee KT (2016) An analysis of the relationship between quality and user acceptance in smartphone apps. Inf Syst E-Bus Manag 14(2):273-291. https://doi.org/10.1007/s10257-015-0283-6

Oliver C (1990) Determinants of interorganizational relationships: integration and future directions. Acad Manag Rev 15(2):241-265. https://doi.org/10.5465/amr.1990.4308156

Oliver C (1991) Strategic responses to institutional processes. Acad Manag Rev 16(1):145-179. https ://doi.org/10.5465/amr.1991.4279002

Palmatier R, Dant R, Grewal D (2007) A comparative longitudinal analysis of theoretical perspectives of interorganizational relationship performance. J Mark 71(4):172-194. https://doi.org/10.1509/ jmkg.71.4.172

Pedersen AB, Risius M, Beck R (2019) A ten-step decision path to determine when to use blockchain technologies. MIS Q Executive 18(2):99-115. https://doi.org/10.17705/2msqe.00010

Powell WW (1990) Neither market nor hierarchy: network forms of organization. Res Organ Behav 12:295-336

Premkumar GP (2000) Interorganization systems and supply chain management: an information processing perspective. Inf Syst Manag 17(3):56-69. https://doi.org/10.1201/1078/43192 $.17 .3 .20000601 / 31241.8$

Rai A, Patnayakuni R, Seth N (2006) Firm performance impacts of digitally enabled supply chain integration capabilities. MIS Q 30(2):225-246. https://doi.org/10.2307/25148729

Rauchs M, Glidden A, Gordon B, Pieters GC, Recanatini M, Rostand F, Zhang BZ (2018) Distributed ledger technology systems-a conceptual framework. SSRN Electron J. https://doi.org/10.2139/ ssrn. 3230013

Ritchie J, Lewis J (2003) Qualitative research practice: a guide for social science students and researchers. Sage, London. https://doi.org/10.4135/9781452230108

Ritter T, Gemünden HG (2003) Network competence: its impact on innovation success and its antecedents. J Bus Res 56(9):745-755. https://doi.org/10.1016/S0148-2963(01)00259-4

Rodón J, Sesé F (2010) Analysing IOIS adoption through structural contradictions. Euro J Inf Syst 19(6):637-648. https://doi.org/10.1057/ejis.2010.44

Sankaranarayanan R, Sundararajan A (2010) Electronic markets, search costs, and firm boundaries. Inf Syst Res 21(1):154-169. https://doi.org/10.1287/isre.1090.0235

Schmitz K, Webb K, Teng J (2010) Exploring technology and task adaptation among individual users of mobile technology. In: Proceedings of the international conference on information systems, ICIS, 2010. Retrieved from https://aisel.aisnet.org/icis2010_submissions/57/

Scholz TM, Stein V (2018) The architecture of blockchain organization. In: Proceedings of the international conference on information systems, ICIS, 2018

Sewell WH Jr (1989) Toward a theory of structure: duality agency and transformation. Am J Sociol 98(1):1-29 
Shin N, Kim D, Park S, Oh J (2018) The moderation effects of mobile technology advancement and system barrier on m-commerce channel preference behavior. Inf Syst E-Bus Manag 16(1):125154. https://doi.org/10.1007/s10257-017-0345-z

Suddaby R (2010) Editor's comments: construct clarity in theories of management and organization. Acad Manag Rev 35(3):346-357. https://doi.org/10.5465/AMR.2010.51141319

Tapscott D, Tapscott A (2017) How blockchain will change organizations. MIT Sloan Manag Rev 58(2):10-13. https://doi.org/10.7551/mitpress/11645.003.0010

Teo HH, Wei KK, Benbasat I (2017) Predicting intention to adopt interorganizational linkages: an institutional perspective. MIS Q 27(1):19-49. https://doi.org/10.2307/30036518

Vargo SL, Akaka MA (2012) Value cocreation and service systems (Re) formation: a service ecosystems view. Serv Sci 4(3):207-217. https://doi.org/10.1287/serv.1120.0019

Venkatesh V, Davis FD (2000) A theoretical extension of the technology acceptance model: four longitudinal field studies. Manage Sci 46(2):186-204. https://doi.org/10.1287/mnsc.46.2.186.11926

Venkatesh V, Morris MG, Davis GB, Davis FD (2003) User acceptance of information technology: toward a unified view. MIS Q 27(3):425-478

Wang YY, Luse A, Townsend AM, Mennecke BE (2015) Understanding the moderating roles of types of recommender systems and products on customer behavioral intention to use recommender systems. Inf Syst E-Bus Manag 13(4):769-799. https://doi.org/10.1007/s10257-014-0269-9

Weill P, Woerner SL (2015) Thriving in an increasingly digital ecosystem. MIT Sloan Manag Rev 56(4):27-34. https://doi.org/10.1287/isre.1100.0318

Whetten DA, Felin T, King BG (2009) The practice of theory borrowing in organizational studies: current issues and future directions. J Manag 35(3):537-563. https://doi.org/10.1177/01492 06308330556

Wu CC, Huang Y, Hsu CL (2014) Benevolence trust: a key determinant of user continuance use of online social networks. Inf Syst E-Bus Manag 12(2):189-211. https://doi.org/10.1007/s1025 7-013-0216-1

Wu IL, Chang CH (2012) Using the balanced scorecard in assessing the performance of e-SCM diffusion: a multi-stage perspective. Decis Support Syst 52(2):474-485. https://doi.org/10.1016/j. dss.2011.10.008

Yli-Huumo J, Ko D, Choi S, Park S, Smolander K (2016) Where is current research on Blockchain technology?-A systematic review. PLoS ONE 11(10):1-27. https://doi.org/10.1371/journ al.pone. 0163477

Yuan Y, Lai F, Chu Z (2019) Continuous usage intention of Internet banking: a commitment-trust model. Inf Syst E-Bus Manag 17(1):1-25. https://doi.org/10.1007/s10257-018-0372-4

Zaheer A, Gözübüyük R, Milanov H (2010) It's the connections: the network perspective in interorganizational research. Acad Manag Perspect 24(1):62-77. https://doi.org/10.5465/AMP.2010.50304417

Zaheer A, McEvily B, Perrone V (1998) Does trust matter? Exploring the effects of interorganizational and interpersonal trust on performance. Organ Sci 9(2):141-159. https://doi.org/10.2307/2640350

Publisher's Note Springer Nature remains neutral with regard to jurisdictional claims in published maps and institutional affiliations. 